\title{
Endoscopic ultrasound-guided forceps biopsy from upper gastrointestinal subepithelial lesions using a forward-viewing echoendoscope
}

Authors

Institutions
Ippei Matsuzaki', Ryoji Miyahara', Yoshiki Hirooka², Kohei Funasaka², Takeshi Yamamura², Eizaburo Ohno', Masanao Nakamura ${ }^{1}$, Hiroki Kawashima ${ }^{1}$, Osamu Watanabe ${ }^{1}$, Makoto Kobayashi $^{3}$, Yoshie Shimoyama ${ }^{4}$, Shigeo Nakamura ${ }^{4}$, Hidemi Goto ${ }^{1}$

Institutions are listed at the end of article. submitted

8. November 2015 accepted after revision 7. March 2016

\section{Bibliography}

DOI http://dx.doi.org/ 10.1055/s-0042-106204 Endoscopy International Open 2016; 04: E637-E641

(c) Georg Thieme Verlag KG Stuttgart . New York E-ISSN 2196-9736

\section{Corresponding author} Ryoji Miyahara, MD PhD Department of

Gastroenterology and Hepatology

Nagoya University Graduate School of Medicine 65

Tsurumai-cho

Showa-ku

Nagoya

466-8550

Japan

Fax: +81-52-7442180

myhr@med.nagoya-u.ac.jp
Background and study aims: Endoscopic tissue acquisition techniques using needle-knife and biopsy forceps allow abundant tissue acquisition from upper gastrointestinal subepithelial lesions; however, these techniques cannot capture realtime intratumor information. The aim of this study was to evaluate the feasibility of endoscopic ultrasound-guided forceps biopsy (EUS-FB) from upper gastrointestinal subepithelial lesions using a forward-viewing echoendoscope.

Patients and methods: This study was a prospective case series. After mucosal cuts, several specimens were taken using a hot biopsy forceps under real-time EUS visualization. The incision was closed using hemoclips. Diagnostic yield, rate of

\section{Introduction \\ $\nabla$}

Endoscopic ultrasound-guided fine-needle aspiration (EUS-FNA) has become accepted as an accurate technique for tissue acquisition from upper gastrointestinal subepithelial lesions [1-3]. We have also reported the usefulness of a newly developed forward-viewing echoendoscope with regard to sample area [4]. On the other hand, endoscopic tissue acquisition techniques using snare, needle-knife and biopsy forceps allow abundant tissue acquisition; however, these techniques cannot capture real-time intratumor information [5-7].

We hypothesized that a forceps biopsy using a forward-viewing echoendoscope could be a useful new endoscopic tissue acquisition technique under EUS visualization. The aim of this study was to evaluate the feasibility of EUS-guided forceps biopsy (EUS-FB) from upper gastrointestinal subepithelial lesions. diagnosable samples obtained under EUS visualization, procedure time, and adverse events were assessed.

Results: Ten patients (median lesion size $16 \mathrm{~mm}$, range $15-44 \mathrm{~mm}$ ) underwent EUS-FB. The overall rate of histological diagnosis by EUS-FB was $100 \%$ (10/10). The rate of diagnosable samples among all cases was $97.6 \%$ (41/42). The median procedure times for EUS-FB and complete closure were 28.5 and 4.5 minutes, respectively. No adverse events occurred.

Conclusions: This newly developed EUS-FB is feasible and allowed forceps biopsy from upper gastrointestinal subepithelial lesions.

Study registration: UMIN000015364

\section{Materials and methods \\ $\nabla$}

This prospective trial was conducted at the $\mathrm{Na}$ goya University Hospital in Japan. Between January 2015 and April 2015, all 10 patients with upper gastrointestinal subepithelial lesions were examined with a radial scanner (GF-UM2000; Olympus Medical Systems Corp., Tokyo, Japan) before EUS-FB.

The inclusion criterion for the study was the presence of an upper gastrointestinal subepithelial lesion. Exclusion criteria were as follows: age $>90$ years; tumor size $<1.5 \mathrm{~cm}$; diagnosis of lipoma or cyst by EUS; and lack of patient's consent. This study was approved by the institutional review board of Nagoya University (IRB No.2014-0300), and written informed consent was obtained from all participating patients. This study was registered in the University Hospital Medical Information Network Clinical Trials Registry (UMIN-CTR) as study number: UMIN0000015364.

\section{Echoendoscope}

All EUS-FB procedures were performed using a forward-viewing echoendoscope (TGF-UC260J; Olympus) by an experienced endoscopist (I.M.) 


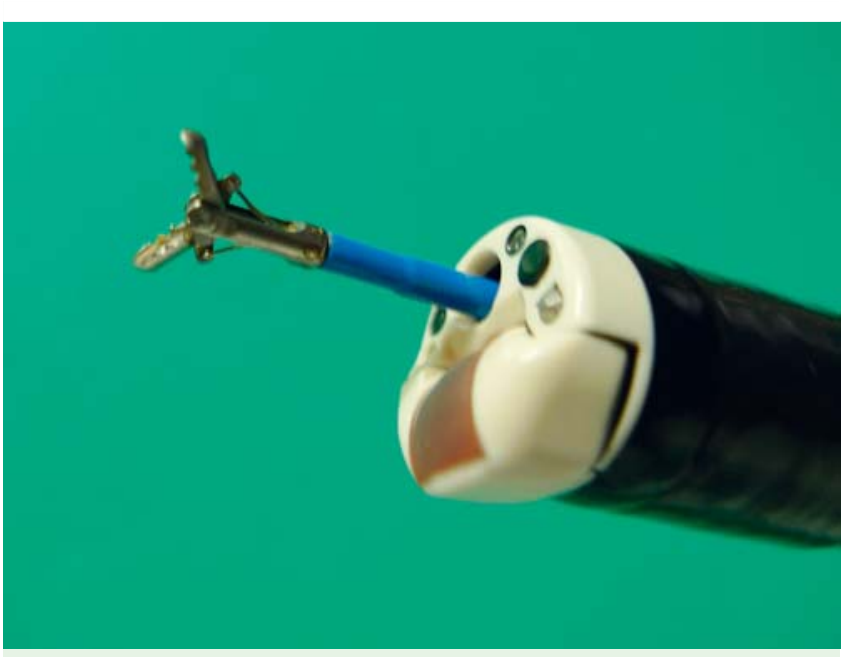

Fig. 1 Forward-viewing echoendoscope with a hot biopsy forceps.

who had performed both endoscopic submucosal dissection (ESD) and EUS on more than 200 upper gastrointestinal lesions. This echoendoscope provides a forward endoscopic view, allows device deployment along the axis of the scope, and has a larger tip angulation compared with the oblique-viewing echoendoscope.

\section{EUS-FB procedure}

All patients were placed in the left lateral position under conscious or deep sedation with intravenous anesthesia using midazolam and pentazocine.

First, the lesion was observed and color flow mapping was applied to avoid thick vessels using a forward-viewing echoendoscope and an ultrasound processor with color Doppler function (EU-ME2; Olympus). Second, a mucosal cut was made by hot biopsy forceps (FD-210U; Olympus) with a PulseCut Fast mode setting of 40W using an electrosurgical unit (ESG-100; Olympus) after injection of saline into the submucosa ( Fig. 1). After mucosal and submucosal cuts, several specimens were taken within the lesion using this forceps without coagulation under real-time EUS visualization. The forceps biopsies were repeated until two whitish tissues were obtained macroscopically, with a maximum of six biopsies. On-site pathologists were not present to determine the adequacy of specimens in this study. Finally, the incision site was closed using hemoclips (HX-610-090L; Olympus) to achieve hemostasis and to avoid exposure of tumor. A broad- spectrum antibiotic and a proton pump inhibitor were administered for 5 days. Patients were hospitalized for 3 days.

\section{Histological assessment}

The collected specimens were immediately placed in formalin and embedded in paraffin for histological examination. The pathological diagnosis was made on the basis of hematoxylineosin staining and immunopathological stains by expert pathologists (Y.S., S.N).

\section{Outcome measures}

The primary end point was the diagnostic yield of the EUS-FB. The secondary end points were the number of mucosal cuts before biopsy of the lesion, the rates of diagnosable samples obtained under EUS visualization, and the procedure times for both EUS-FB and complete closure. Adverse events were defined as any deviation from the clinical course after EUS-FB. All patients were contacted within 1 month of the procedure to assess whether there had been any late adverse events.

\section{Statistical analysis}

Continuous variables such as patients' age and tumor size were reported as median and range. Comparisons of proportions such as diagnostic yield, rates of diagnosable samples, and adverse events were expressed as frequencies and proportions.

\section{Results}

$\nabla$

During this study period, 10 patients ( 7 males and 3 females; median age 63 years, range $31-77$ years) underwent EUS-FB. Tumor locations were esophagus in two cases, stomach in five cases, and duodenum in three cases. The median tumor size was $16 \mathrm{~mm}$ (range 15-44 mm). Layers of origin were the submucosa in two cases and the muscularis propria in eight cases. Patterns of growth were intraluminal in seven cases, extraluminal in one case, and mixed in two cases ( Table 1 ). The overall rate of histological diagnosis of EUS-FB was $100 \%(10 / 10)$. The median number of mucosal cut biopsies was 3.5 (range 1-11) and the rate of diagnosable samples among the 10 cases was $97.6 \%$ (41/ 42). Abundant tissue fragments without cautery artifact and without blood contamination were obtained from all cases. The histologic results of EUS-FB were gastrointestinal stromal tumor (GIST), mitotic index $<5 / 50(n=1)(\diamond$ Fig. 2$)(\diamond$ Video 1$)$, leiomyoma $(n=4)$, schwannoma $(n=1)$, malignant lymphoma $(n=1)$, neuroendocrine tumor, Ki-67 $3-5 \%(n=1)$, ectopic pancreas $(n=1)$, and Brunner's gland hyperplasia $(n=1)$. Median procedure times

Table 1 Characteristics of patients with subepithelial lesions.

\begin{tabular}{|cllll|}
\hline Case & Age, years/sex & Tumor location & Tumor size, mm & Wall layer of origin on EUS \\
\hline 1 & $33 / \mathrm{M}$ & Duodenum, bulb, PW & 16 & Muscularis propria \\
\hline 2 & $77 / \mathrm{F}$ & Stomach, middle body, LC & 21 & Muscularis propria \\
\hline 3 & $66 / \mathrm{M}$ & Duodenum, bulb, AW & 15 & Submucosa \\
\hline 4 & $31 / \mathrm{M}$ & Stomach, upper body, GC & 44 & Muscularis propria \\
\hline 5 & $72 / \mathrm{M}$ & Stomach, upper body, LC & 15 & Muscularis propria \\
\hline 6 & $75 / \mathrm{M}$ & Duodenum, bulb, PW & 15 & Submucosa \\
\hline 7 & $71 / \mathrm{M}$ & Stomach, middle body, GC & 16 & Muscularis propria \\
\hline 8 & $35 / \mathrm{M}$ & Esophagus, middle, AW & 31 & Muscularis propria \\
\hline 9 & $34 / \mathrm{F}$ & Stomach, lower body, GC & 20 & Muscularis propria \\
\hline 10 & $60 / \mathrm{F}$ & Esophagus, cervical, AW & 15 & Muscularis propria \\
\hline
\end{tabular}

PW, posterior wall; LC, lesser curvature; AW, anterior wall; GC, greater curvature. 

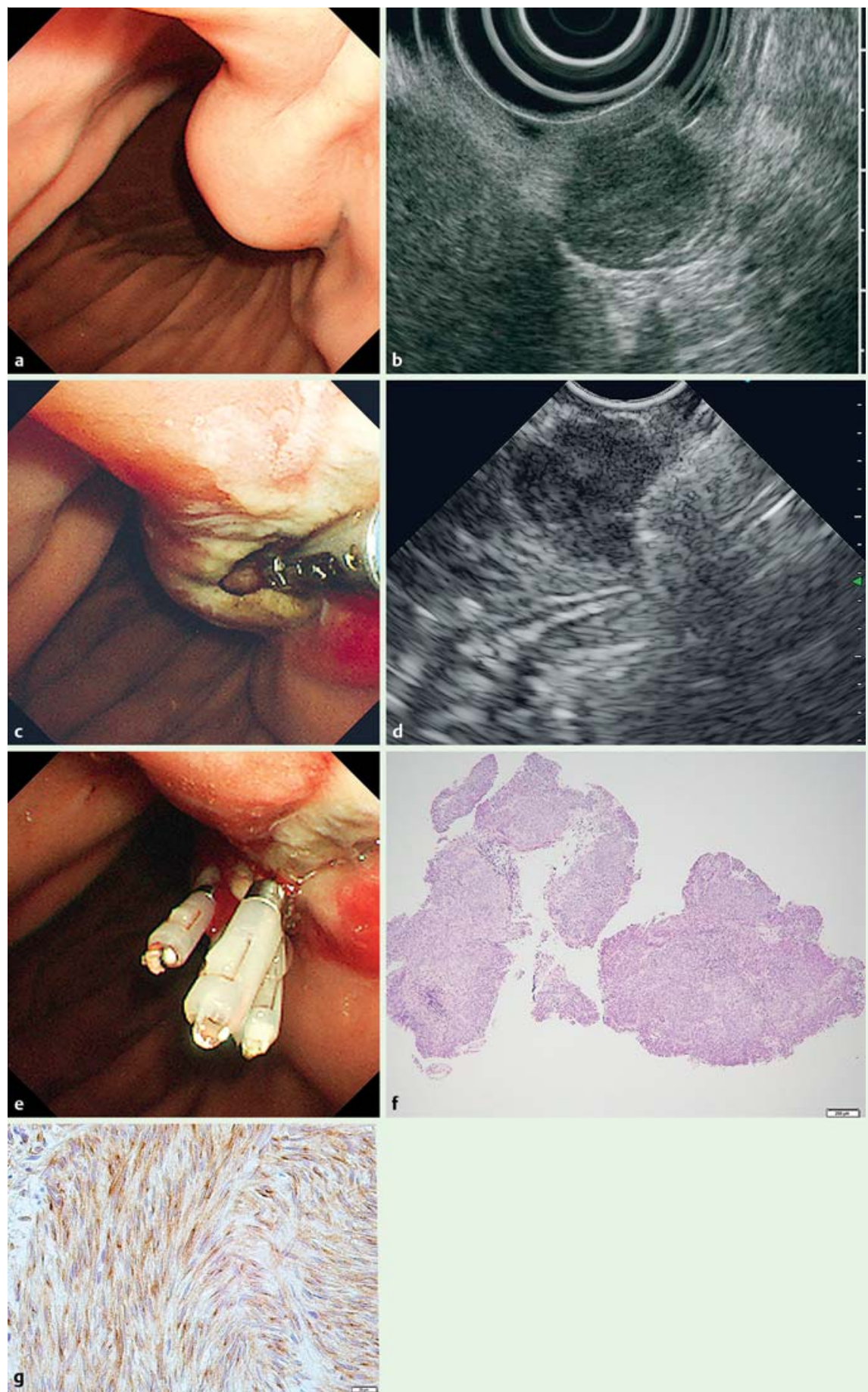

for EUS-FB and complete closure were 28.5 minutes (range 9-46 minutes) and 4.5 minutes (range 3-32 minutes), respectively ( $\bullet$ Table 2). No adverse events occurred.

\section{Discussion}

$\nabla$

EUS-FBs using the forward-viewing echoendoscope for upper gastrointestinal subepithelial lesions were successfully performed without adverse events. Histopathological diagnoses including immunopathological stains and mitotic index assessments were obtained in all cases.

The prognostication of GISTs is based on the mitotic index, and gastrointestinal subepithelial lesions less than $2 \mathrm{~cm}$ have a low
Fig.2 Representative case of a gastrointestinal stromal tumor (case 5) diagnosed using EUS-FB. a Endoscopy showing subepithelial lesion in the upper body of the stomach. $\mathbf{b}$ EUS image with radial scanner. The hypoechoic tumor was $15 \mathrm{~mm}$ and a heterogeneous echo pattern was located in the muscularis propria. c Endoscopic view of the EUS-FB shows the forceps entering the subepithelial lesion after mucosal cut. d EUS image showing the open forceps within the subepithelial lesion. e Incision closed using hemoclips. f Abundant tissue fragments without contamination showing a spindlecell neoplasm (hematoxylin and eosin stain; magnification $\times 40$ ). $\mathbf{g}$ Tumor is diffusely positive for c-kit (immunohistochemical stain for c-kit; magnification $\times 400$ ) risk of malignant behavior $[8,9]$. Theoretically, early diagnosis and early treatment are promising means of obtaining a permanent cure. All six subepithelial lesions less than $2 \mathrm{~cm}$ were diagnosed in this study. A small tumor size was thought to be one of the factors related to a nondiagnostic result for EUS-FNA $[2,4]$. Therefore, the EUS-FB technique is thought to be suitable for all gastrointestinal subepithelial lesions including small tumor sizes. The diagnostic yield from EUS-FNA ranged from $83 \%$ to $93 \%$ [13]. Recently, we reported the usefulness of EUS-FNA using a forward-viewing echoendoscope with regard to sample area [4]. However, the mitotic and proliferative assessments using FNA are thought to be difficult. On the other hand, unroofing and cutting biopsy techniques allowed abundant tissue acquisition safely ( Table 3) [5-7]; however, these reported techniques could not 
Table 2 Outcome of EUS-guided forceps biopsy.

\begin{tabular}{|c|llllll|}
\hline Case & $\begin{array}{l}\text { Number of muco- } \\
\text { sal cuts before } \\
\text { biopsy of lesion }\end{array}$ & $\begin{array}{l}\text { Number of } \\
\text { samples within } \\
\text { tumor* }\end{array}$ & $\begin{array}{l}\text { Number of diag- } \\
\text { nosable samples } \\
\text { by pathology }\end{array}$ & $\begin{array}{l}\text { Procedure time } \\
\text { for EUS-FB, min }\end{array}$ & $\begin{array}{l}\text { Procedure time for } \\
\text { complete closure, } \\
\text { min }\end{array}$ & EUS-FB diagnosis \\
\hline 1 & 3 & 5 & 5 & 44 & 32 & Heterotopic pancreas \\
\hline 2 & 5 & 6 & 6 & 34 & 4 & Malignant lymphoma \\
\hline 3 & 1 & 2 & 2 & 28 & 4 & Brunner's gland hyperplasia \\
\hline 4 & 1 & 5 & 5 & 29 & 4 & Leiomyoma \\
\hline 5 & 7 & 2 & 2 & 19 & 5 & GIST, mitotic index $<5 / 50$ HPF \\
\hline 6 & 1 & 4 & 3 & 9 & 14 & Leuroendocrine tumor, Ki-67 3 -5\% \\
\hline 7 & 9 & 3 & 3 & 31 & 3 & Leiomyoma \\
\hline 8 & 4 & 6 & 6 & 19 & 9 & Schwannoma \\
\hline 9 & 11 & 5 & 5 & 46 & 3 & Leiomyoma \\
\hline 10 & 1 & 4 & 4 & 13 & 11 & \\
\hline
\end{tabular}

GIST, gastrointestinal stromal tumor; HPF, high power field.

* Tissue samples were taken under EUS visualization.

Table 3 Comparison of endoscopic tissue acquisition techniques from subepithelial lesions apart from EUS-guided FNA.

\begin{tabular}{|llllllll}
\hline Author, year & Technique & Devices & $\begin{array}{l}\text { No. of } \\
\text { patients }\end{array}$ & $\begin{array}{l}\text { Tumor size, medi- } \\
\text { an (range), mm }\end{array}$ & $\begin{array}{l}\text { Diagnostic } \\
\text { yield }\end{array}$ & $\begin{array}{l}\text { Rates of mitotic } \\
\text { index evaluation }\end{array}$ & $\begin{array}{l}\text { Adverse } \\
\text { events }\end{array}$ \\
\hline Lee et al. [5], 2010 & $\begin{array}{l}\text { Unroofing } \\
\text { technique }\end{array}$ & $\begin{array}{l}\text { Electrosurgical } \\
\text { snare }\end{array}$ & 16 & $16(11-25)$ & $93.8 \%(15 / 16)$ & $100 \%(6 / 6)$ \\
\hline $\begin{array}{l}\text { de la Serna-Higuera et } \\
\text { al. [6], 2011 }\end{array}$ & $\begin{array}{l}\text { EUS-guided single- } \\
\text { incision; needle- } \\
\text { knife biopsy }\end{array}$ & $\begin{array}{l}\text { Needle-knife, } \\
\text { biopsy forceps }\end{array}$ & 14 & $31(12-64)$ & $92.9 \%(13 / 14)$ & $62.5 \%(5 / 8)$ \\
\hline Kobara et al. [7], 2013 & Bloc biopsy & Needle-knife & 8 & $20(8-40)$ & $100 \%(8 / 8)$ & $100 \%(6 / 6)$ & $0 \%$ \\
\hline $\begin{array}{l}\text { Matsuzaki et al., this } \\
\text { study }\end{array}$ & $\begin{array}{l}\text { EUS-guided } \\
\text { forceps biopsy }\end{array}$ & Hot biopsy forceps & 10 & $16(15-44)$ & $100 \%(10 / 10)$ & $100 \%(1 / 1)$ & $0 \%$ \\
\hline
\end{tabular}

capture real-time intratumor information using an echoendoscope.

Recently, EUS-guided through-the-needle forceps biopsy was reported [10]. This technique allows tissue acquisition within the lesion using forceps under EUS guidance. However, this technique required 19 gauge needle puncture and miniforceps. Furthermore, the feasibility with regard to diagnosis of subepithelial lesions was not clarified. In this study, forward endoscopic view and device deployment along the axis of the scope could allow

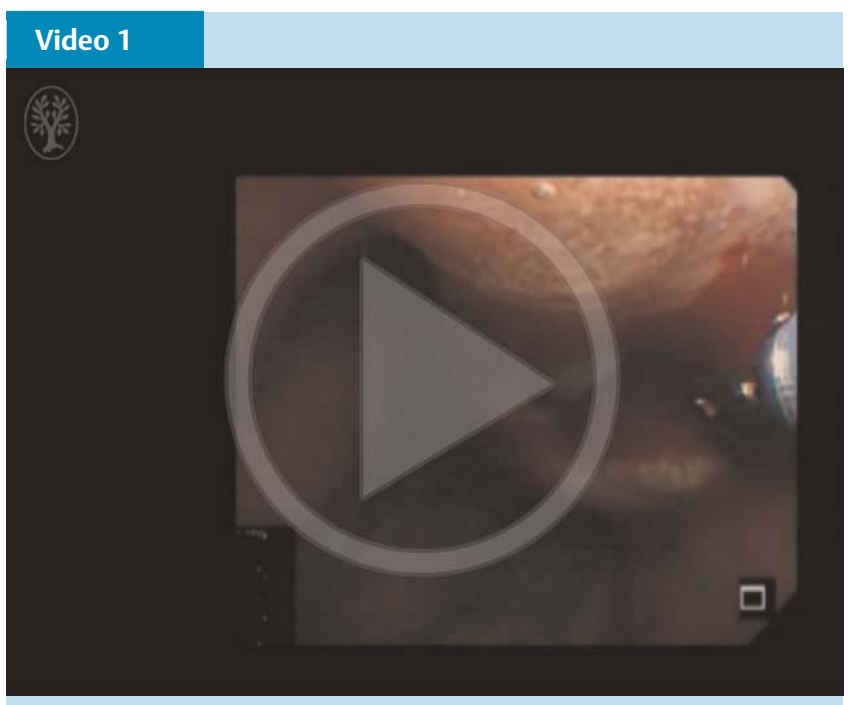

EUS-guided forceps biopsy from upper gastrointestinal subepithelial lesion. Online content including video sequences viewable at: http://dx.doi.org/ $10.1055 / \mathrm{s}-0042-106204$ forceps biopsy from subepithelial lesions under real-time EUS guidance using the forward-viewing echoendoscope. The realtime intratumor information and the depth of forceps within the tumor could be confirmed using this echoendoscope. On the other hand, care should be taken not to burn the distal end of the echoendoscope when using hot biopsy forceps. This technique cannot be easily and safely performed using an oblique-viewing echoendoscope.

In this study, adequate tissues were obtained using hot biopsy forceps in all cases including eight subepithelial lesions originating from muscularis propria. Furthermore, the rate of diagnosable samples was $97.6 \%(41 / 42)$ in this study. The diagnostic accuracy of EUS-guided forceps biopsy may be higher than for conventional endoscopic tissue acquisition techniques including EUS-FNA; however, in some cases, several mucosal cutting biopsies were performed to insert the forceps into tumors because of slip. The improved prehensile hot biopsy forceps or needle-knife may be suitable for this technique.

Procedural blood oozing was common and was treated using unroofing and cutting biopsy techniques [5-7]. In our study, electrosurgical current using hot biopsy forceps and complete closure of the incision sites could prevent this adverse event. Furthermore, no infectious adverse events occurred. This technique may not require antibiotics and hospitalization.

Theoretically, this EUS-FB technique is suitable for all subepithelial lesions. This may be especially advantageous for small lesions less than $2 \mathrm{~cm}$ and extraluminal growth lesions.

In conclusion, this study clearly demonstrated the feasibility of this newly developed EUS-FB using a forward-viewing echoendoscope for upper gastrointestinal subepithelial lesions. Stud- 
ies with a larger sample size are needed to further evaluate this procedure.

\section{Competing interests: None}

\section{Institutions}

${ }^{1}$ Department of Gastroenterology and Hepatology, Nagoya University Graduate School of Medicine, Nagoya, Japan

2 Department of Endoscopy, Nagoya University Hospital, Nagoya, Japan

${ }^{3}$ Department of Gastroenterology, Yokkaichi Municipal Hospital, Mie, Japan

${ }^{4}$ Department of Pathology and Clinical Laboratories, Nagoya University Hospital, Nagoya, Japan

\section{Acknowledgments}

We thank Olympus Medical System for the loan of the forwardviewing echoendoscope to our unit.

\section{References}

1 Matsui M, Goto H, Niwa $Y$ et al. Preliminary results of fine needle aspiration biopsy histology in upper gastrointestinal submucosal tumors. Endoscopy 1998; 30: 750 - 755

2 Mekky MA, Yamao K, Sawaki A et al. Diagnostic utility of EUS-guided FNA in patients with gastric submucosal tumors. Gastrointest Endosc 2010; 71: $913-919$
3 Larghi A, Fuccio L, Chiarello G et al. Fine-needle tissue acquisition from subepithelial lesions using a forward-viewing linear echoendoscope. Endoscopy 2014; 46: 39-45

4 Matsuzaki I, Miyahara R, Hirooka Yet al. Forward-viewing versus oblique-viewing echoendoscopes in the diagnosis of upper GI subepithelial lesions with EUS-guided FNA: a prospective, randomized, crossover study. Gastrointest Endosc 2015; 82: 287-295

5 Lee CK, Chung IK, Lee SH et al. Endoscopic partial resection with the unroofing technique for reliable tissue diagnosis of upper GI subepithelial tumors originating from the muscularis propria on EUS (with video). Gastrointest Endosc 2010; 71: 188-194

6 de la Serna-Higuera C, Pérez-Miranda M, Díez-Redondo P et al. EUSguided single-incision needle-knife biopsy: description and results of a new method for tissue sampling of subepithelial GI tumors (with video). Gastrointest Endosc 2011; 74: 672 - 676

7 Kobara H, Mori H, Fujihara $S$ et al. Bloc biopsy by using submucosal endoscopy with a mucosal flap method for gastric subepithelial tumor tissue sampling (with video). Gastrointest Endosc 2013; 77: 141 - 145

8 Fletcher CD, Berman JJ, Corless C et al. Diagnosis of gastrointestinal stromal tumors: A consensus approach. Hum Pathol 2002; 33: 459-465

9 Miettinen M, Lasota J. Gastrointestinal stromal tumors: pathology and prognosis at different sites. Semin Diagn Pathol 2006; 23: 70-83

10 Samarasena JB, Nakai Y, Shinoura $S$ et al. EUS-guided, through-theneedle forceps biopsy: a novel tissue acquisition technique. Gastrointest Endosc 2015; 81: 225 - 226 